\title{
Effect of Applied load on Tribological Study of Hybrid Metal Matrix Composites
}

\author{
B.M. Viswanatha, M. Prasanna Kumar, S. Basavarajappa and T.S. Kiran
}

\begin{abstract}
In the present article to studies on microstructure, mechanical and tribological properties of aluminium MMCs reinforced with silicon carbide $\left(\mathrm{SiC}_{\mathrm{p}}\right)$ and graphite $(\mathrm{Gr})$ particles were carried out. A356 alloy is used as the aluminium based matrix material with varying the reinforcement of $\mathrm{SiC}_{\mathrm{p}}$ from 0 to 9 wt. \% in steps of 3 wt. \% and fixed quantity of 3 wt. $\%$ of graphite. The specimens were fabricated by stir-cast method. The prepared specimens were examined using optical microscope to know the particle distribution in the matrix. Hardness, tensile and wear tests were carried out for specimen. The wear test was carried out using pin-on disc wear testing machine with varying applied load. From the results, it was observed that the composite showed higher hardness and tensile strength as compared to the base alloy. The presence of reinforcements $\left(\mathrm{SiC}_{\mathrm{p}}\right.$ and $\left.\mathrm{Gr}\right)$ significantly affects the solid state transition kinetics that improves the properties of composites. The significant improvement in strength and wear resistance was obtained for composite when compared to the base alloy specimen. The worn out surfaces and wear debris of specimen were analyzed using (scanning electron microscope) SEM and electron dispersive spectroscopy (EDS).
\end{abstract}

Index Terms - EDS, Hardness, Microstructure, MMCs, Tensile strength, SEM, Wear rate.

\section{INTRODUCTION}

A composite can be defined as an engineered material consisting of a matrix and a reinforcing material. These two constituents give the composite the superior properties that are expected from that material [1], [2].Matrix selection not only involves desired properties but also decides the material which is best suited for composite manufacturing. In case of matrix selection, factors such as density, ductility, toughness and strength retention at elevated temperature are considered. Generally, aluminium (Al), magnesium $(\mathrm{Mg})$, zinc $(\mathrm{Zn})$, titanium $(\mathrm{Ti})$ and copper $(\mathrm{Cu})$ are matrix materials.

Aluminium-silicon (Al-Si) alloys have found wide application because of their wide range of properties. These alloys are quite compatible with almost all ceramic reinforcements. It is possible to produce reliable $\mathrm{Al}-\mathrm{Si}$ castings because of their excellent castability. Aluminium alloy alone shows poor mechanical and tribological

Published on September 30, 2016. This work was part of my research work. Effect of Applied load on Tribological Study of hybrid Metal Matrix Composites.

B. M. Viswanatha is with the Mechanical Engineering Department, Kalpataru Institute of Technology, Tiptur, 572202, India (e-mail: vishwanathabm@gmail.com).

M. Prasanna Kumar is with the Department of studies in Mechanical Engineering, University B.D.T. College of Engineering, Davanagere, 577004, India (e-mail: drmpkumar.dvg@ gmail.com).

S. Basavarajappa is with the Registrar, Indian Institute of Information Technology, Dharwad, 580029, India (e-mail: basavarajappas@yahoo.com).

T. S. Kiran is with the Mechanical Engineering Department, kalpataru Institute of Technology, Tiptur, 572202, India (e-mail: kirants111@gmail.com). properties that led to the development of new materials [3], [4]. Most of the research work on MMCs is carried out on silicon carbide particle $\left(\mathrm{SiC}_{\mathrm{p}}\right)$, aluminium oxide $\left(\mathrm{Al}_{2} \mathrm{O}_{3}\right)$ and graphite $(\mathrm{Gr})$ particles alone while few researchers have worked on the combination of reinforcements (hybrid composites) [5], [6].

The simplest and the most cost effective method of liquid state fabrication is stir-casting method. Liquid state fabrication methods are particularly suited for production of composite parts that are complex in shape. Stir-casting is also referred as vortex method. The reinforcement phase (particle, short fibers, whiskers etc) is introduced through the sides of a vortex created in the melt with a mechanical impeller to form slurry. At the end of the stirring, the slurry is poured into die and allowed to solidify and prepare the specimen for respective tests [7]-[10].

PRMMCs exhibit attractive mechanical properties such as high tensile strength and fatigue resistance, optimum ductility and fracture behavior. Elastic modulus increases with addition of reinforcement but is independent on the type of reinforcement [11].

The development of new materials that can operate in the severe conditions has become a major imperative. The dry sliding wear of $\mathrm{A} 356-\mathrm{SiC}_{\mathrm{p}}$ composites were studied using pin-on-disc machine [12]-[14]. The results concluded that composites possess improved wear resistance compared with the base alloy. The improved wear resistance is due to addition of $\mathrm{SiC}_{\mathrm{p}}$ which reduces the propensity of material flow at the surface. Reference [15] worked on wear behavior of Al-12\% Si alloy reinforced with a low volume fraction of $\mathrm{SiC}_{\mathrm{p}}$ prepared by compocasting technique. The results showed that the addition of low volume fraction of $\mathrm{SiC}_{\mathrm{p}}$ is an effective way to increase the wear resistance. Reference [16] studied the sliding wear behavior of $\mathrm{Al}-\mathrm{SiC}_{\mathrm{p}}$ composites. At low applied load, the small size of particles lead to severe wear at high speed and specimen experiences melting. The composite with small $\mathrm{SiC}_{\mathrm{p}}$ are suitable for lower-speed applications [17]. Reference [18] studied the wear mechanisms of $\mathrm{A} 356$ alloy and $\mathrm{A} 356-20 \mathrm{SiC}_{\mathrm{p}}$ composite material. They reported that the addition of $\mathrm{SiC}_{\mathrm{p}}$ to alloy leads to mild wear regime at higher speeds and loads, there by inhibiting severe wear.

Reference [19] studied the wear behaviour of Al2024$5 \mathrm{Gr}$ composites. The composites exhibits better wear resistance compared with base alloy. The lower Gr (2-5 wt. $\%)$ shows higher wear resistance than higher $\mathrm{Gr}$ content $(5$ to $20 \mathrm{wt}$ \%). Increasing the $\mathrm{Gr}$ in matrix forms porosity and cracks that decrease the mechanical property resulting in delamination. Reference [20] studied the tribological properties of A356-Gr with varying $\mathrm{Gr}$ content $(2,4,6$ and 8 wt. \%). The results showed that up to $6 \mathrm{wt}$. $\%$ of graphite particles, composites exhibit lowest wear rate compared to 8 wt. \%. The sliding speed and normal load had less influence on wear rate. Reference [21] studied the wear properties of Al-Si alloy reinforced with 3 wt. $\%$ of $\mathrm{Gr}$ at elevated 
temperatures. They concluded that wear resistance increases by addition of Gr compared with the base alloy.

Reference [22] studied the effect of addition of $\mathrm{Gr}$ in composites $\left(\mathrm{Al}-\mathrm{SiC}_{\mathrm{p}}\right)$ on tribological behavior. The results showed that the addition of $\mathrm{Gr}$ reduces the hardness and CTE. The addition of $\mathrm{Gr}$ reduces the friction coefficient and wear becomes more stable resulting in smaller wear debris. Reference [23] studied the role of tribo-layers on sliding wear behaviour of $\mathrm{A} 356-10 \mathrm{SiC}_{\mathrm{p}}-4 \mathrm{Gr}$ and $\mathrm{A} 356-5 \mathrm{Al}_{2} \mathrm{O}_{3}-4 \mathrm{Gr}$ hybrid composites. They reported that a thicker and more stable tribo-layer on the hybrid composites was observed than that of non-graphitic composites and base alloy. Reference [24] reported that the increase in wear resistance of $\mathrm{Al}-\mathrm{SiC}_{\mathrm{p}}-\mathrm{Gr}$ composites was due to increase of $\mathrm{Gr}$ particle size. The tribolayers enhanced with increasing graphite particle size that improves the wear resistance avoiding plastic deformation and reducing metal-metal contact between sliding pair [25]. Reference [26] reported the wear behaviour of $\mathrm{Al}-\mathrm{SiC}_{\mathrm{p}}-\mathrm{Gr}$ hybrid composites. They exhibit better wear resistance compared to composites reinforced with $\mathrm{SiC}_{\mathrm{p}}$ alone. This is due to the presence of solid lubricant ( $\mathrm{Gr}$ particles) that is released during sliding and forming a tribolayer at the contact surface. The wear rate increases with increasing sliding distance for any percentage of reinforcement due to unstable $\mathrm{MML}$ in $\mathrm{Al}-\mathrm{SiC}_{\mathrm{p}}$ composites. The fractured $\mathrm{SiC}_{\mathrm{p}}$ causes further scratching on the surface of the composites that make the MML unstable [27]-[32].

\section{EXPERIMENTAL PROCEDURES}

\section{A. Aluminium Matrix Material}

The base alloy (A356) is the popular matrix among all aluminium (Al) alloys because of its low density, superior thermal, electrical properties, corrosion resistance and improved damping capacity. The details of matrix material composition and properties are shown in Table I and Table II respectively [33].

TABLE I: COMPOSITION OF A356 BASE ALLOY

\begin{tabular}{l|c|c|c|c|c|c|c|l|l}
\hline Elements & $\mathrm{Cu}$ & $\mathrm{Mg}$ & $\mathrm{Mn}$ & $\mathrm{Si}$ & $\mathrm{Fe}$ & $\mathrm{Zn}$ & $\mathrm{Ti}$ & Others & $\mathrm{Al}$ \\
$\begin{array}{l}\text { Weight } \\
\%\end{array}$ & 0.1 & 0.4 & 0.06 & 7.0 & 0.1 & 0.04 & 0.1 & Traces & Balance \\
\hline
\end{tabular}

TABLE II: MECHANICAL PROPERTIES OF A356, T6 TREATMENT

$\begin{array}{lcccc}\text { Material } & \begin{array}{c}\text { Density } \\ \left(\mathrm{g} / \mathrm{cm}^{3}\right)\end{array} & \begin{array}{c}\text { Yield } \\ \text { strength } \\ (\mathrm{MPa})\end{array} & \begin{array}{c}\text { Tensile } \\ \text { strength } \\ (\mathrm{MPa})\end{array} & \begin{array}{c}\text { Hardness } \\ (\mathrm{BHN})\end{array} \\ \text { A356,T6 } & 2.685 & 185 & 262 & 80\end{array}$

\section{B. Particle Reinforcements}

The prime purpose of the reinforcement is to provide strength and stiffness to the composite. The characteristic of particles depends on the size and distribution of particles, matrix-particles interface bond strength. MMCs are used for high temperature applications to provide creep strength and high temperature tensile strength. Silicon carbide particles $\left(\mathrm{SiC}_{\mathrm{p}}\right.$, average size of $\left.25 \mu \mathrm{m}\right)$ are used in the fabrication and the properties are shown in Table 3 [34]. It is a compound of silicon and carbon that is used as abrasive. Graphite ( $\mathrm{Gr}$ ) is one of the allotropes of carbon. Gr holds the distinction of being the most stable form of carbon under standard conditions. Graphite powder is valued in industrial applications for its self-lubricating and dry lubricating properties. The mechanical properties of $\mathrm{Gr}$ are shown in Table IV [34].

\begin{tabular}{cccll}
\multicolumn{5}{c}{ TABLE III: MECHANICAL PROPERTIES OF SIC } \\
\hline Material & $\begin{array}{l}\text { Density } \\
\left(\mathrm{g} / \mathrm{cm}^{3}\right)\end{array}$ & $\begin{array}{l}\text { Yield } \\
\text { strength } \\
(\mathrm{MPa})\end{array}$ & $\begin{array}{l}\text { Tensile } \\
\text { strength } \\
(\mathrm{MPa})\end{array}$ & $\begin{array}{l}\text { Hardness, } \\
(\mathrm{BHN})\end{array}$ \\
& 3.2 & 400 & 100 & 81 \\
\hline
\end{tabular}

TABLE IV: MECHANICAL PROPERTIES OF GRAPHITE

\begin{tabular}{ccccc}
\hline Material & $\begin{array}{c}\text { Density } \\
\left(\mathrm{g} / \mathrm{cm}^{3}\right)\end{array}$ & $\begin{array}{c}\text { Yield } \\
\text { strength } \\
(\mathrm{MPa})\end{array}$ & $\begin{array}{c}\text { Tensile } \\
\text { strength } \\
(\mathrm{MPa})\end{array}$ & $\begin{array}{c}\text { Hardness } \\
(\mathrm{BHN})\end{array}$ \\
Graphite & 1.82 & 292 & 371 & 40 \\
\hline
\end{tabular}

\section{B. Reinforcements}

The prime purpose of the reinforcement is to provide strength and stiffness to the composite. The characteristic of particles depends on the size and distribution of particles, matrix-particles interface bond strength. MMCs are used for high temperature applications to provide creep strength and high temperature tensile strength. Silicon carbide particles $\left(\mathrm{SiC}_{\mathrm{p}}\right.$, average size of $\left.25 \mu \mathrm{m}\right)$ are used in the fabrication and the properties are shown in Table III [34]. It is a compound of silicon and carbon that is used as abrasive.

\section{Fabrication of Composites using Stir-cast Technique}

Fabrication of the base alloy and composites were carried out by stir-casting technique and as shown in Fig. 1. A known weight of A356 billets were placed inside the graphite crucible and the electrical furnace temperature is set to $750^{\circ} \mathrm{C}$ (liquidous temperature of base alloy). The $\mathrm{SiC}_{\mathrm{p}}$ was varied from 3, 6 and 9 wt. \% and fixed quantity of 3 wt. $\%$ of $\mathrm{Gr}$ was added to the base alloy. The reinforcements were preheated to avoid the oxide formation and improve the bonding between matrix and reinforcements. A mechanical stirrer is used to stir the liquid alloy (500 rpm) to create a vortex and the preheated reinforcements are added to the melt. The degasification agent hexachloroethane $\left(\mathrm{C}_{2} \mathrm{Cl}_{6}\right)$ is added to remove the entrapped gas from the molten mixture. The preheated mold box is placed on sand bed in order to avoid spilling of molten metal while pouring. After solidification, the castings were removed from the mold box and the specimens were prepared as per ASTM standards.

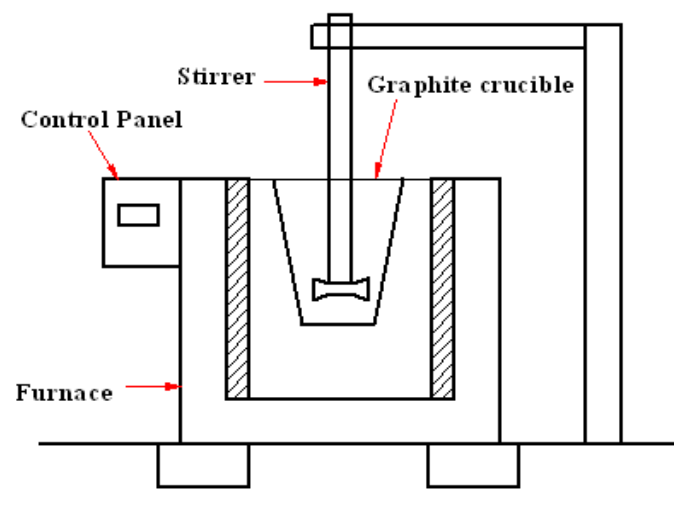

Fig. 1 Electrical crucible furnace 


\section{CHARACTERIZATION OF MECHANICAL PROPERTIES}

The as-castand aged specimens were used to evaluate the microstructure and mechanical properties such as hardness and tensile strength.

\section{A. Microstructure}

To evaluate the microstructure of the base alloy and composites, polishing was carried out on Mecapol P230 polishing machine. Fine polishing was done to get mirror like finish using alumina powder. Keller's reagent was used as etchant. The polished specimens were used to study the distribution of reinforcements in the matrix. Nikon Microscope LV150 with Clemex image analyzer was used to evaluate the microstructure of the specimen.

\section{B. Hardness Test}

The hardness of the specimen was measured on a Vickers hardness testing machine with an applied load of 2 $\mathrm{kgf}$ for a period of 10 seconds. The hardness tests were conducted as per ASTM E-92 standard. The results were analyzed on an average of 3 readings. The diamond indenter was used for the test. The degree of accuracy was influenced by the surface finish of the specimen. The resulting unrecovered indentation diagonals are measured and average will give a value in millimeters. These length measurements are used to calculate the Vickers hardness number (VHN).

The Vickers indenter has included face angles of $136^{\circ}$ and the Vickers hardness number is calculated using the equation 2.1 .

$\mathrm{HV}=\frac{1.8544 \mathrm{p}}{\mathrm{d}^{2}}$

Where, ' $p$ ' is the indentation load in kgf and ' $d$ ' is the mean diagonal of indentation in $\mathrm{mm}$. The hardness was measured on composites and base alloy for as-cast and aged specimens.

\section{Tensile Test}

Tensile test is one of the most commonly used tests for evaluating materials. The tensile specimens were prepared using standard templates. The specimens were machined according to the ASTM E-8M standard. Tensile strength was measured on composites and base alloy for both as-cast and aged material.

\section{Dry sliding wear Test}

The wear test was carried out on DUCOM pin-on-disc machine is shown in Fig. 2 to evaluate the dry sliding wear behavior of the as-cast and aged specimens as per ASTM G98-99 standard. The tests were carried out by keeping the specimen against a rotating steel disc (EN-36) with hardness of $65 \mathrm{HRc}$. The surface roughness $(\mathrm{Ra})$ of both the specimens was $0.3 \mu \mathrm{m}$. The wear specimen was machined to $8 \mathrm{~mm}$ in diameter and $30 \mathrm{~mm}$ in height from the cast sample and then polished metallographically. The initial and final weight of each specimen was measured on a electronic weighing machine with accuracy of $0.0001 \mathrm{gm}$. The tests were conducted at room temperature with varying applied load from 10 to $50 \mathrm{~N}$. The surface of specimen and disc were cleaned before each test with acetone. The wear rates of the specimen were calculated using (2.2 to 2.4) and the worn out surface of test specimen was observed by SEM (JEOL, JSM-6360). The difference of weight between the initial and final mass of the specimen gives the weight loss due to wear calculated using (2.2). The volume loss was calculated using (2.3). The wear rate of the specimens was carried out by using ratio of volume loss to sliding distance was calculated using (2.4).

Weight loss $=$ Initial weight - Final weight $(\mathrm{gm})$

Volume loss $=\frac{\text { Weight loss }}{\text { Density of the specimens }}\left(\mathrm{mm}^{3}\right)$
Wear rate $=\frac{\text { Volume loss }}{\text { Distance }}\left(\frac{\mathrm{mm}^{3}}{\mathrm{~m}}\right)$

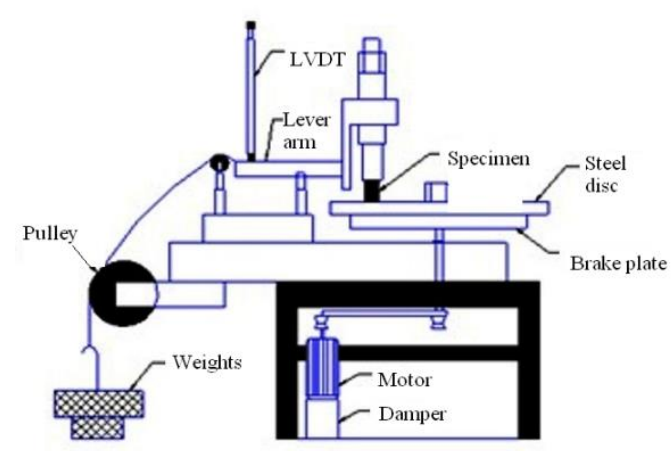

Fig. 2 Pin-on-disc wear testing machine

\section{RESULTS}

In this section, brief discussion of the microstructure and mechanical properties of the base alloy and composites of as-cast and aged specimens were studied.

\section{A. Microstructure}

Microstructure of as-cast specimen is shown in Fig. 3. The microstructure of A356 base alloy (Fig. 3a) and A356 reinforced with fixed $3 \mathrm{wt}$. \% of $\mathrm{Gr}$ and varying 3 to $9 \mathrm{wt}$. \% in steps of 3 wt. $\%$ of $\mathrm{SiC}_{\mathrm{p}}$ are shown in Fig. 3(b-d) respectively.
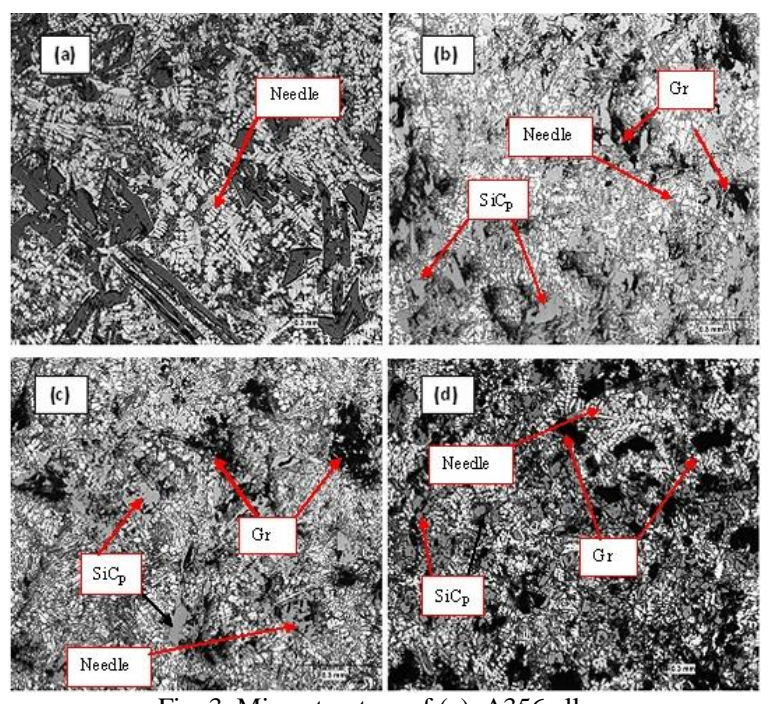

Fig. 3. Microstructure of (a). A356 alloy

(b). A356-3\% Gr-3\% $\mathrm{SiC}$

(c). A356-3\% Gr- $6 \% \mathrm{SiC}_{\mathrm{p}}(\mathrm{d}) . \mathrm{A} 356-3 \% \mathrm{Gr}-9 \% \mathrm{SiC}_{\mathrm{p}}$ 
Microstructure of base alloy (Fig. 3a) consists of fine dendrites of aluminium solid solutions $(\alpha)$ with fine eutectic silicon particles having needle shape at interdendritic regions. The uniform distribution of the reinforcements is as shown in Fig. 3 (b-d). In Fig. 3 (b-d) coarser $\mathrm{SiC}_{\mathrm{p}}$ was observed and $\mathrm{Gr}$ particles were well associated with $\mathrm{SiC}_{\mathrm{p}}$. The inter particle spacing is found to play a crucial role in determining the properties. The finer microstructure and homogeneous particle distribution improves the properties of the composites. The amount of reinforcements present in 9 wt. $\%$ of $\mathrm{SiC}_{\mathrm{p}}$ (Fig. 3d) is more compared to 3 and 6 wt. $\%$ of $\mathrm{SiC}_{\mathrm{p}}$ (Fig. 3, b and c).

\section{B. Hardness}

The hardness of specimen was measured using Vickers diamond indenter and the indentation is shown in Fig. 4. The hardness of the composites improved by $9 \%$, with an addition of 3 wt. $\%$ of $\mathrm{SiC}_{\mathrm{p}}$ and $\mathrm{Gr}$ particles. Further addition of reinforcements showed minor improvement in hardness (Fig. 5).

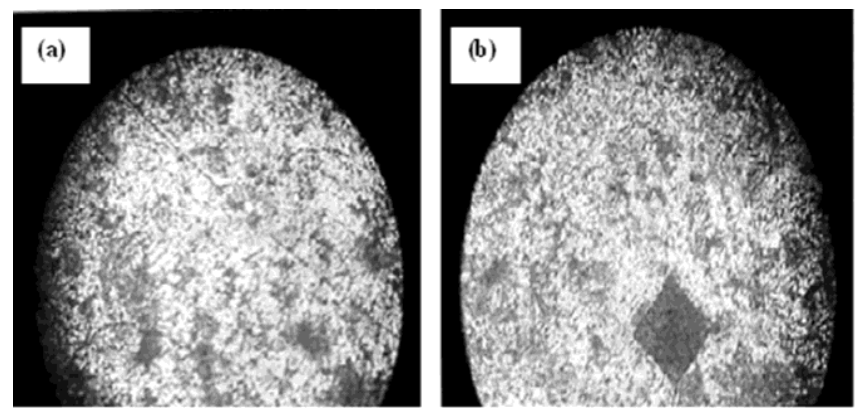

Fig. 4. (a). Before Indentation at 100x (b). After Indentation at 100x

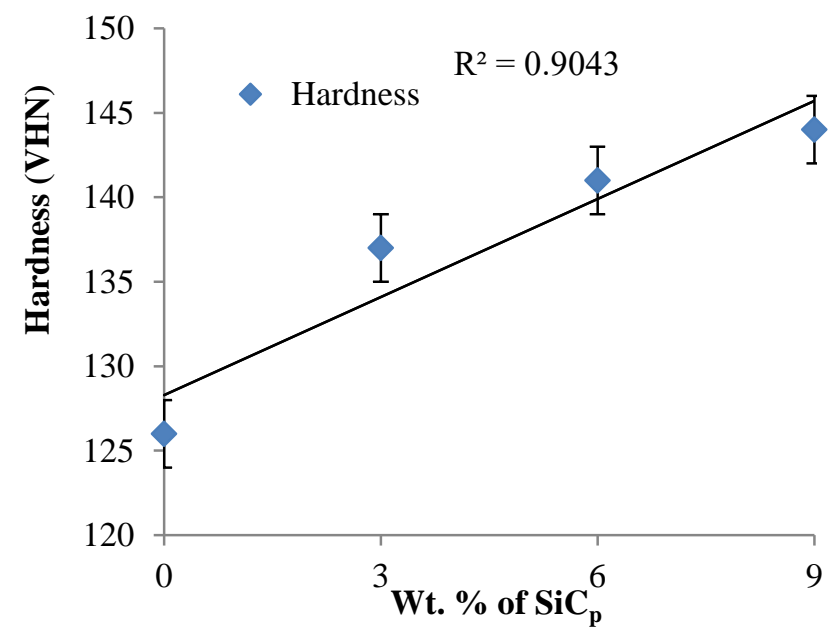

Fig. 5 Effect on hardness by addition of $\mathrm{SiC}_{\mathrm{p}}$ with $\mathrm{A} 356$ matrix material

\section{Tensile Strength}

The tensile strength of the composites increased with increase in $\mathrm{SiC}_{\mathrm{p}}$ as shown in Fig. 6. The tensile strength of the composites improved by $5 \%$, with an addition of $3 \mathrm{wt} . \%$ of $\mathrm{SiC}_{\mathrm{p}}$ and $\mathrm{Gr}$ particles. The reinforcement plays a significant role in overall strength of the composites.

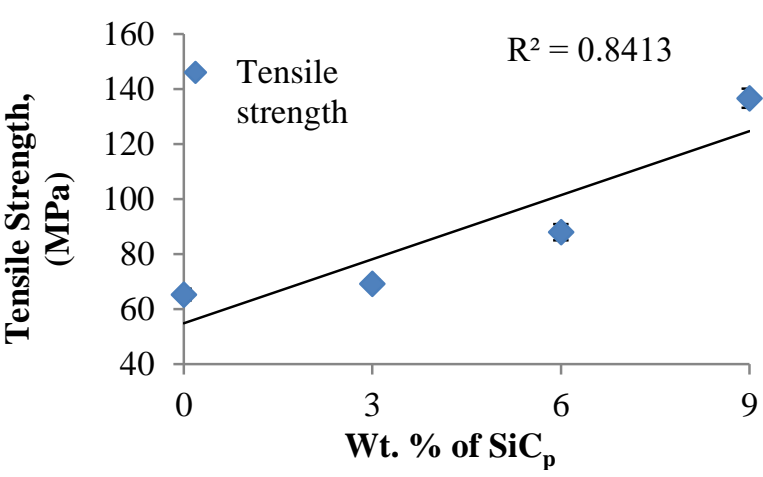

Fig. 6. Effect on tensile strength by addition of $\mathrm{SiC}_{\mathrm{p}}$ with $\mathrm{A} 356$ matrix material

\section{Effect of Applied load on Tribological behavior}

Fig. 7 shows the variation of wear rate with different applied loads at a constant sliding speed of $3.77 \mathrm{~m} / \mathrm{s}$ and sliding distance of $4500 \mathrm{~m}$. The wear rate of the base alloy drastically increased with increasing of applied load. The wear rate increased steadily with increasing the applied load for all composite specimens. The wear rate of $\mathrm{A} 356-9 \mathrm{SiC}_{\mathrm{p}}$ $3 \mathrm{Gr}$ is significantly lower than other combinations. As applied load was low, the wear rate was lower and it increased with increase in applied load. For base alloy, the wear rate increased drastically above $20 \mathrm{~N}$ and it experiences severe wear. For the composite $\left(\mathrm{A} 356-9 \mathrm{SiC}_{\mathrm{p}^{-}}\right.$ $3 \mathrm{Gr}$ ), the severe wear region was absent up to $50 \mathrm{~N}$. The increase of $\mathrm{SiC}_{\mathrm{p}}$ to A356-Gr composites increased the wear resistance of the composites.

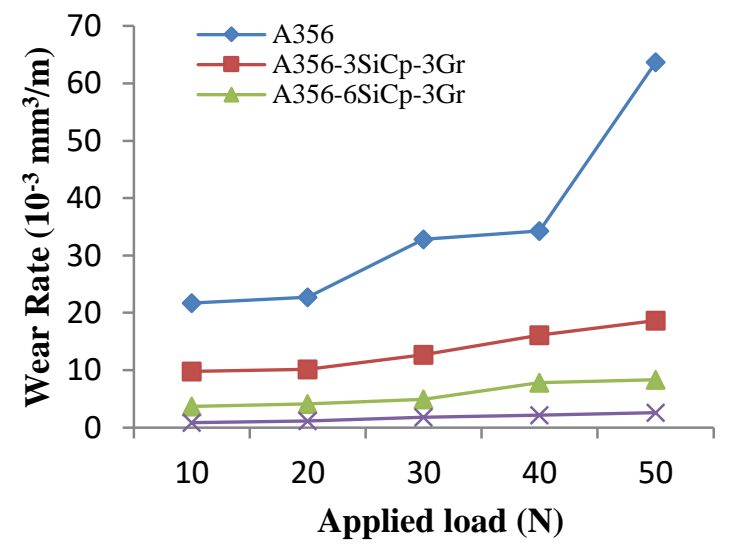

Fig. 7 Variations of wear rate with different applied loads, at constant sliding speed $3.77 \mathrm{~m} / \mathrm{s}$ and sliding distance $4500 \mathrm{~m}$

\section{DISCUSSION}

\section{A. Microstructure and Mechanical Properties}

By liquid metallurgy technique (vortex method), particle size of $25-44 \mu \mathrm{m}\left(\mathrm{SiC}_{\mathrm{p}}-\mathrm{Gr}\right)$ were dispersed in the matrix. The uniform distribution of particles in the composite is influenced by the type, shape of reinforcement and speed of rotation of the stirrer [9-10]. The creation of vortex during stirring is essential for piercing of the particles inside the melt medium. Suitable aerofoil shaped blades were used for improvement in dispersion of reinforcements. The distribution of reinforcements is dependent on the solidification rates. Longer the solidification rate, more uniform is the distribution of the reinforcements in the matrix [33-34]. The uniform distribution of $\mathrm{SiC}_{\mathrm{p}}$ and $\mathrm{Gr}$ (Fig. 3, b-d) is observed within the interdendritic region. 
The reinforcements are found to be pushed by $\alpha-\mathrm{Al}$ dendrites to the interdendtrictic regions. Thus, reinforcements are segregated along dendritic boundaries with higher cooling rate leading to finer dendrite cell size which gives finer inter particle spacing [11].

In case of composites, when the $\mathrm{SiC}_{\mathrm{p}}$ and $\mathrm{Gr}$ particles are added to $\mathrm{Al}$ matrix, extensive interfacial reactions are present in equations 4.1 and 4.2. Interfacial reactions enhance the load bearing capabilities and lubrication properties of MMCs. Extensive interfacial reactions are accelerated by high processing temperature. $\mathrm{SiC}_{\mathrm{p}}$ and $\mathrm{Gr}$ react with molten aluminium and the following products were obtained.

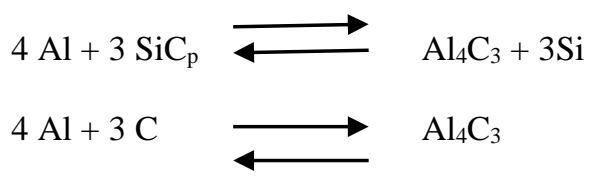

In case of first reaction (4.1), aluminium carbide $\left(\mathrm{Al}_{4} \mathrm{C}_{3}\right)$ layer is formed through solid state diffusion and in the second reaction (4.2) by the dissolution of $\mathrm{Gr}(\mathrm{C})$ into liquid $\mathrm{Al}$ to form $\mathrm{Al}_{4} \mathrm{C}_{3}$. The brittle $\mathrm{Al}_{4} \mathrm{C}_{3}$ phase results from the reactions between $\mathrm{SiC}_{\mathrm{p}}$ or $\mathrm{Gr}$ with $\mathrm{Al}$. $\mathrm{Al}_{4} \mathrm{C}_{3}$ deteriorates the mechanical properties of the composites, thus avoiding the formation of $\mathrm{Al}_{4} \mathrm{C}_{3}$ as the primary concern for successful fabrication [33].

The formation of $\mathrm{Al}_{4} \mathrm{C}_{3}$ is avoided by decreasing the possible reaction between molten $\mathrm{Al}$ and reinforcements. The $\mathrm{SiC}_{\mathrm{p}}$ and $\mathrm{Gr}$ reinforcements are preheated to $600^{\circ} \mathrm{C}$, which induce the formation of silicon oxide $\left(\mathrm{SiO}_{2}\right)$ layer on the $\mathrm{SiC}_{\mathrm{p}}$. The oxide layer prevents direct contact between the $\mathrm{SiC}_{\mathrm{p}}$ and molten $\mathrm{Al}$ and this inhibits the formation of $\mathrm{Al}_{4} \mathrm{C}_{3}$. The $\mathrm{Gr}$ particles with high degree of graphitization do not readily react with molten $\mathrm{Al}$ because their chemical properties are relatively stable that inhibits the interfacial reaction of Al-Gr composites [34]. The interface formed between the matrix and reinforcement is important since the characteristic of this region determines the load transfer and crack resistance of the MMCs during deformation. It is accepted that in order to maximize the interfacial bond strength in MMCs, it is necessary to promote wetting and control chemical reactions [7].

The interaction may be in the form of chemical bonding between matrix and the reinforcements, which improves the hardness (Fig.4.3) and tensile strength of the composites with increasing of wt. \% of $\mathrm{SiC}_{\mathrm{p}}$ (Fig. 6). The presence of $\mathrm{SiC}_{\mathrm{p}}$ along with flow lines act as barriers to the movement of dislocations within the matrix. In composites, $\mathrm{SiC}_{\mathrm{p}}$ acts as a load bearing member that enhances the hardness of the material. Similar results were observed for A356-SiC $\mathrm{p}_{\mathrm{p}}$ [34] and $\mathrm{Al}-\mathrm{Si}-\mathrm{SiC}_{\mathrm{p}}$ [12] by earlier researchers. Hardness of the specimen increases with increase in $\mathrm{SiC}_{\mathrm{p}}$ and decreases with increasing reinforcement of $\mathrm{Gr}$ [15]. Inclusion of both $\mathrm{SiC}_{\mathrm{p}}$ and $\mathrm{Gr}$ will not yield as good result when reinforced with $\mathrm{SiC}_{\mathrm{p}}$ alone, as $\mathrm{Gr}$ is a soft reinforcement [35].

The presence of reinforcement in matrix generates dislocation across the span of lattice [36]. The generation of dislocation as a result of heavy pile up of dislocations at the grain boundary as well as the particle-matrix interface causes increase in the strength of composites [37].

\section{B. Tribological behavior}

The wear rate increases with increasing of applied load, sliding speed and sliding distance for the base alloy and composites. The wear rate was maximum for base alloy when compared to the composites. At lower applied load of $20 \mathrm{~N}$, wear rate was constant. This is due to the formation of oxide film between specimen and the disc that avoids the material removal rate. When applied load was increased after $40 \mathrm{~N}$ for base alloy, wear rate increased suddenly. In composites at higher applied loads, the tangential force resulting from softness contact will give rise to a shear stress exceeding the shear strength of the particle-matrix interface. There will be particle debonding, which contributes to an increase in the wear rate [5-6]. At lower applied load, reinforcement particles in the matrix alloy do not get debonded or fractured. The embedded hard $\mathrm{SiC}_{\mathrm{p}}$ and soft $\mathrm{Gr}$ particles in the matrix alloy result in an improved wear resistance of the composites. $\mathrm{SiC}_{\mathrm{p}}$ acts as a load bearing member which increases the higher load carrying capacity of the material. The wear rate increases with increasing of applied load and decreases with the increase of reinforcement. The increase in wear rate with increasing applied load is due to reduced effect of tribolayer, as it weakens the tribolayer formation resulting in shift from mild to severe wear (Fig. 8).

\section{Worn out surfaces}

Fig. 8 reveals the SEM of worn-out surfaces at the loading conditions of applied load at $10 \mathrm{~N}$ and $50 \mathrm{~N}$, with constant sliding speed $3.77 \mathrm{~m} / \mathrm{s}$ and sliding distance of 4500 m. Fig. 8 ( $\mathrm{a}$ and $\mathrm{b}$ ) shows the images of base alloy and Fig. 8 (c and d) shows the images of $\mathrm{A} 356-9 \mathrm{SiC}_{\mathrm{p}}-3 \mathrm{Gr}$ at $10 \mathrm{~N}$ and $50 \mathrm{~N}$ respectively. As $\mathrm{A} 356-9 \mathrm{SiC}_{\mathrm{p}}-3 \mathrm{Gr}$ specimen showed superior wear resistance behaviour over other combination of composites, the SEM of former was considered. More intensive plastic flow of material from the specimen surface occurred at higher applied load of $50 \mathrm{~N}$ (Fig. 8b) and lower material flow occurred at lower applied load of $10 \mathrm{~N}$ (Fig. $8 a)$.
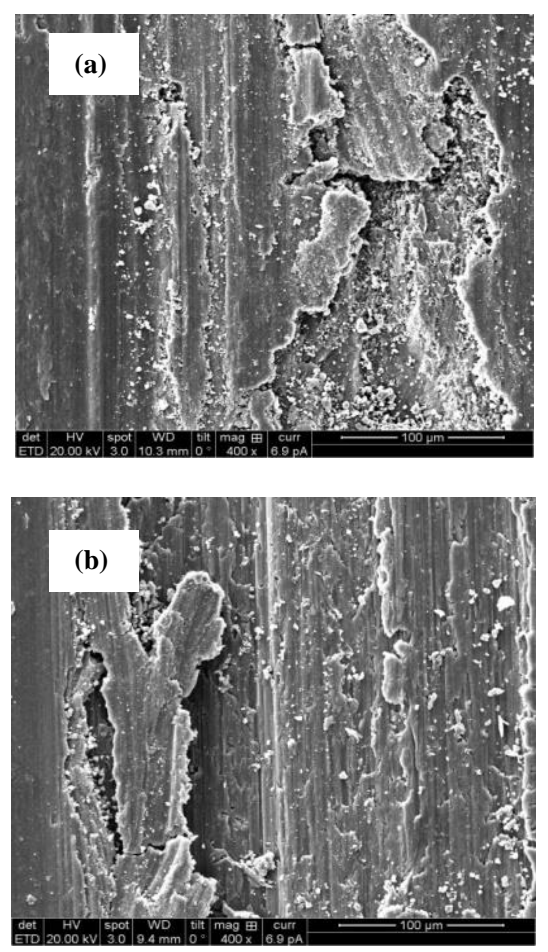

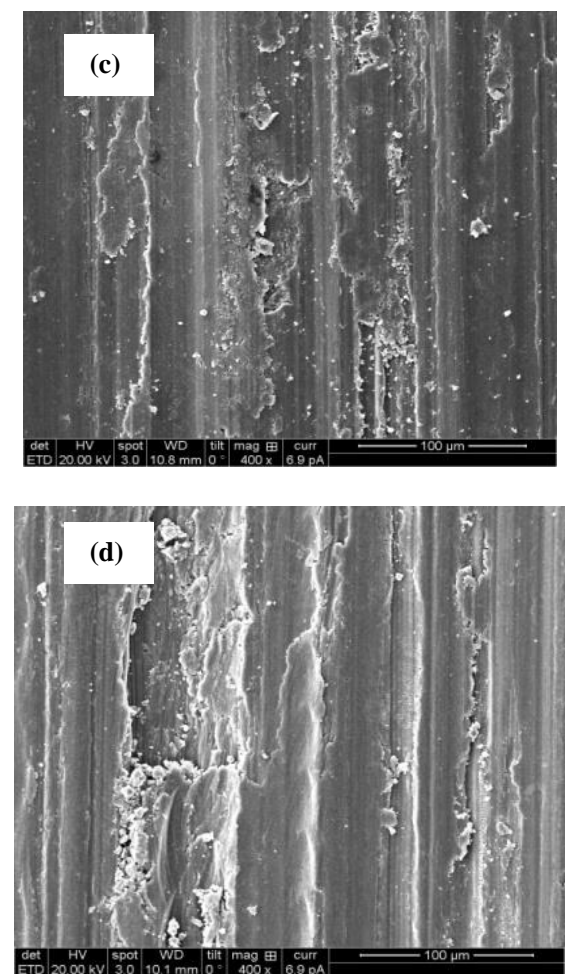

Fig. 8. SEM as-cast worn out surfaces (a) A356 at $10 \mathrm{~N}$ (b) A356 at $50 \mathrm{~N}$ (c) A356-9 $\mathrm{SiC}_{\mathrm{p}}-3 \mathrm{Gr}$ at $10 \mathrm{~N}$ (d) $\mathrm{A} 356-9 \mathrm{SiC}_{\mathrm{p}}-3 \mathrm{Gr}$ at $50 \mathrm{~N}$ and constant sliding speed $(3.77 \mathrm{~m} / \mathrm{s})$ and constant sliding distance $(4500 \mathrm{~m})$

Fig. 8 (The material removed from the specimen was in the form of thin sheet and exhibited plastic deformation which increases the wear rate of the base alloy. Fig. 8 (c and d) shows finer grooves on the surface of the composite specimen. The grooves were formed as $\mathrm{SiC}_{\mathrm{p}}$ penetrates from the specimen surface, which slides against the disc surface. It acts as an abrasive medium that ploughs the surface of the specimen causing wear by removal of negligible material from the specimen. Smeared $\mathrm{Gr}$ present in the matrix reduces the wear rate of the composites when compared to the base alloy [25-26].

The material removal rate is higher for $\mathrm{A} 356-3 \mathrm{SiC}_{\mathrm{p}}-3 \mathrm{Gr}$ and $\mathrm{A} 356-6 \mathrm{SiC}_{\mathrm{p}}-3 \mathrm{Gr}$ than $\mathrm{A} 356-9 \mathrm{SiC}_{\mathrm{p}}-3 \mathrm{Gr}$ composites. Distinct grooves originate due to ploughing of material from the specimen surface. This was confirmed by wear track where the presence of grooves was noticed in Fig. 8 (c and d). This confirms the improved wear resistance of the A356$9 \mathrm{SiC}_{\mathrm{p}}-3 \mathrm{Gr}$ composites. The increase in $\mathrm{SiC}_{\mathrm{p}}$ decreases the wear rate due to increase in contact area of $\mathrm{SiC}_{\mathrm{p}}$ with disc. $\mathrm{SiC}_{\mathrm{p}}$ prevents severe wear by protecting the soft matrix and improving the wear resistance. The projected $\mathrm{SiC}_{\mathrm{p}}$ is crushed at the interface which forms powdered $\mathrm{SiC}_{\mathrm{p}}$ along with ferrous oxides from the steel disc (Fig. 8, c and d). Aluminium oxides from the specimen and smeared reinforcement are mixed to form a mechanically mixed layer (MML). The wear resistance of composite increases, as the hardness of MML is higher than that of the specimen [2832].

The appearance of specimen contact surface were observed at the end of each test and captured with camera (Fig. 9).

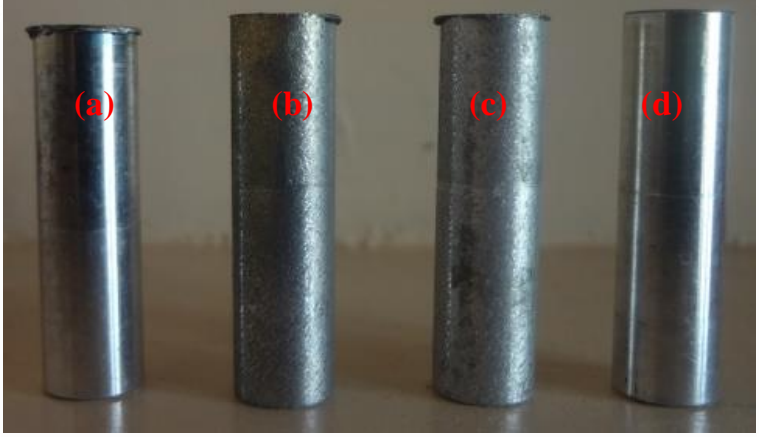

Fig. 9. Appearance of worn out specimens at an applied load $30 \mathrm{~N}$, sliding speed $3.77 \mathrm{~m} / \mathrm{s}$ and sliding distance $4500 \mathrm{~m}$ (a). A356 base alloy (b). A356$3 \mathrm{SiC}_{\mathrm{p}}-3 \mathrm{Gr}(\mathrm{c}) . \mathrm{A} 356-6 \mathrm{SiC}_{\mathrm{p}}-3 \mathrm{Gr}(\mathrm{d}) . \mathrm{A} 356-9 \mathrm{SiC}_{\mathrm{p}}-3 \mathrm{Gr}$

The EDS of worn out surfaces Fig. 10(a and b) shows high peak of $\mathrm{Al}$ and low peak of $\mathrm{Si}$ and $\mathrm{C}$. The high peak indicates plastic deformation of the composites while sliding. The low peaks of $\mathrm{Si}$ indicated that $\mathrm{SiC}_{\mathrm{p}}$ were pulled out from the matrix while sliding and $\mathrm{C}$ peak confirmed the smearing of Gr particles at contact surface (Fig. 10b). The Fe peaks Plastic flow of material from the surface of specimen was noticed. Plastic flow of base alloy was observed at load of $30 \mathrm{~N}$ (Fig. 9a). Less material flowed from $\left(\mathrm{A} 356-3 \mathrm{SiC}_{\mathrm{p}}-3 \mathrm{Gr}\right.$ and $\left.\mathrm{A} 356-6 \mathrm{SiC}_{\mathrm{p}}-3 \mathrm{Gr}\right)$ specimens as shown in Fig. 9 (b and c), while mild wear of specimen (A356-9 $\mathrm{SiC}_{\mathrm{p}}-3 \mathrm{Gr}$ ) was observed from Fig. 9d. The increase of $\mathrm{SiC}_{\mathrm{p}}$ content along with $\mathrm{Gr}$ shows stable MML (Fig. 8, d). The stable wear resistance was observed for $\mathrm{A} 356-9 \mathrm{SiC}_{\mathrm{p}^{-}}$ $3 \mathrm{Gr}$ composite when compared to the other tested specimens.

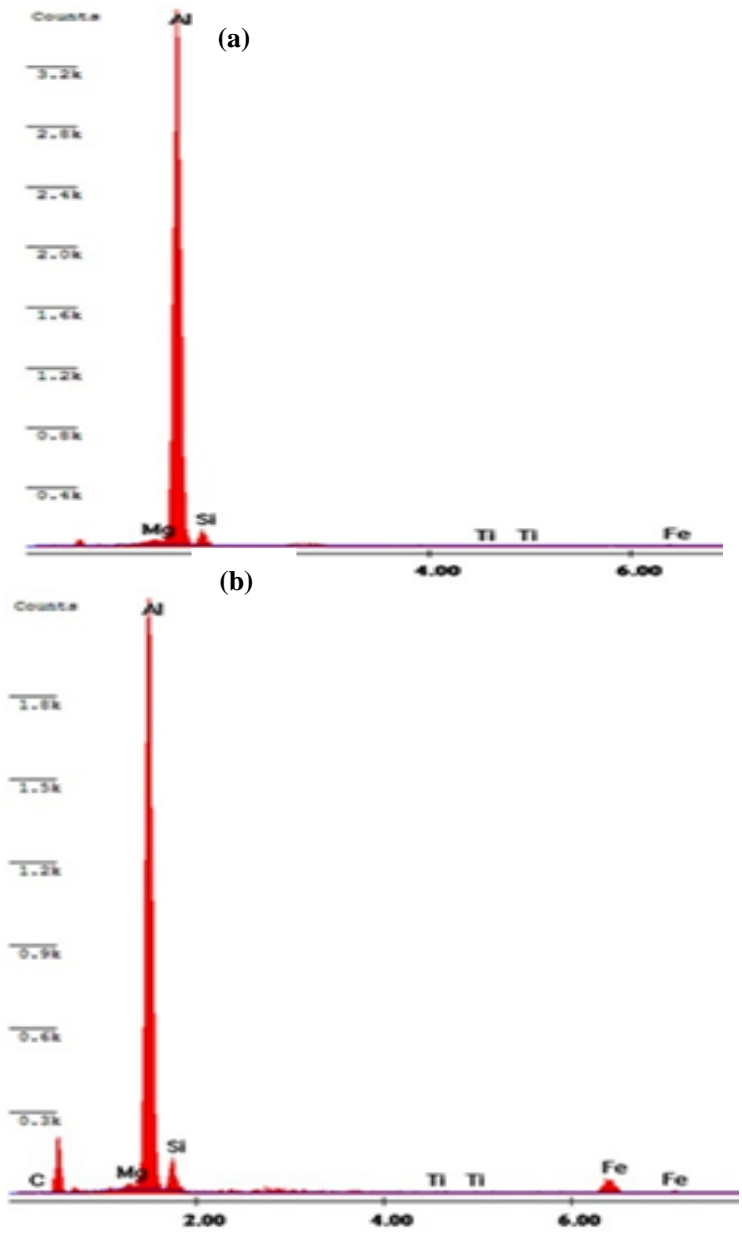

Fig. 10. EDS of worn out surfaces (a) A356-alloy and (b) A356-9SiC $\mathrm{p}^{-}$ $3 \mathrm{Gr}$-composite 


\section{Wear debris}

The wear debris of worn out specimen is as shown in Fig 11. The wear debris of A356 alloy at higher load of 50 $\mathrm{N}$ throws away plate like thin sheets (Fig. 11a). The plate like particles reveals the plastic flow of material from the specimen. The alloy is much softer than the rotating disc and during sliding, rotating disc particles penetrates into matrix forming deep grooves and causing extensive plastic deformation on the surface, which results in more material removal from the specimen surface.

The wear debris of the base alloy observed from the Fig. 11a was large and in the form of thin sheets. This morphology indicates that, base alloy had undergone severe plastic deformations. The wear debris of the composites (Fig. 11b) was small, due to the fractured reinforcement scattered in $\mathrm{Al}$ matrix that minimizes the size of wear debris.
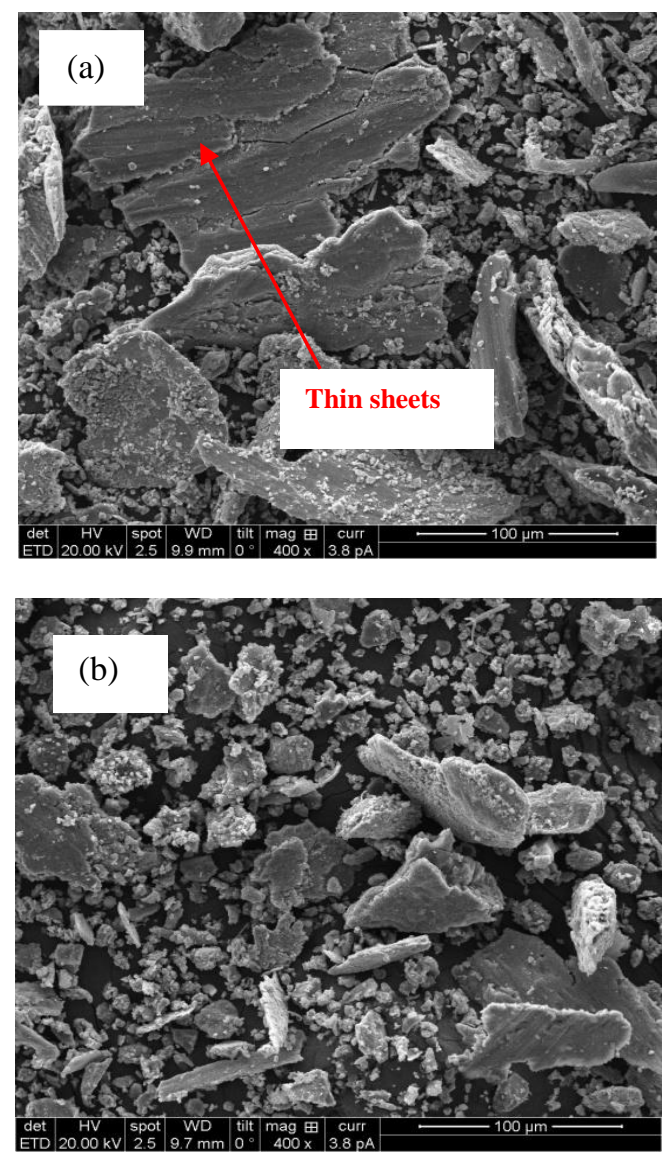

Fig. 11. SEM of as-cast wear debris (a) A356 alloy (b) A356-9SiC $\mathrm{P}_{\mathrm{p}}-3 \mathrm{Gr}$ composite

\section{CONCLUSIONS} drawn.

From the research work, the following conclusions were

A. Fabrication, Microstructure and Mechanical Properties

- A356 base alloy and composites were successfully fabricated by stir-cast method.

- Microstructure shows the uniform dispersion of reinforcements $\left(\mathrm{SiC}_{\mathrm{p}}\right.$ and $\left.\mathrm{Gr}\right)$.

- Microstructure of the A356 base alloy and composites consists of primary aluminium-rich dendrites of $\alpha$ phase. The $\mathrm{SiC}_{\mathrm{p}}$ and $\mathrm{Gr}$ particles are well distributed in the eutectic and interdendritic region in composites.
- After ageing of the specimen, microstructure consists of modified fine rounded eutectic silicon dispersed in the interdendritic region and fine precipitates of alloying elements in the matrix of Al solid solution. The particles are well dispersed in the matrix.

- The hardness is improved by $9 \%$ and tensile strength is $5 \%$ improved in the $\mathrm{A} 356-9 \mathrm{SiC}_{\mathrm{p}}-3 \mathrm{Gr}$ composite compared with the base alloy.

\section{B. Dry Sliding wear behavior}

- The A356-9SiC $\mathrm{S}_{\mathrm{p}}-3 \mathrm{Gr}$ composites showed minimum wear rate when compared with other tested composites and base alloy.

- The wear rate of the Al-based composites is dependent on the reinforcement and wear resistance increased with the increase in the percentage of reinforcement.

- The A356-9 $\mathrm{SiC}_{\mathrm{p}}-3 \mathrm{Gr}$ composites showed superior wear resistance compared with 3,6 wt. \% of $\mathrm{SiC}_{\mathrm{p}}$.

- $\quad \mathrm{A} 356-9 \mathrm{SiC}_{\mathrm{p}}-3 \mathrm{Gr}$ composite forms a stable MML, due to $\mathrm{SiC}_{\mathrm{p}}$ and $\mathrm{Gr}$ reinforcements. This mechanism is not present in the base alloy and other tested composites resulting in increase of wear rate.

- SEM studies of the worn out surfaces revealed that severe plastic deformation of the base alloy and mild wear for the composites were observed.

- It is confirmed by EDS analysis of the worn out surfaces of composites that the presence of reinforcements along with iron.

\section{REFERENCES}

[1]. P. K. Rohatgi, "Metal Matrix Composites", Defence Science Journal, Vol. 43, No 4, pp. 323-349, October 1993.

[2]. S.V. Prasad and R. Asthana, "Aluminium Metal Matrix Composites for Automotive Applications: Tribological Considerations”, Tribology Letter, Vol. 17, No. 3, pp. 445-452, October 2004.

[3]. M. K. Surappa, "Aluminium Matrix Composites: Challenges and Opportunities", Sadhana, Vol. 28, pp. 319-334, 2003.

[4]. M. A. Taha, "Practicalization of Cast Metal Matrix Composites (MMCs)", Materials and Design, Vol.22, pp.431-441, 2001.

[5]. W. Ames and A.T Alpas, "Wear Mechanism in Hybrid Composites of graphite-20 Pct. SiC in A356 Aluminium alloy (Al-7 Pct. Si-0.3 Pct. Mg)", Metallurgical and Materials Transactions, Vol. 26A, pp.85-97, 1995 .

[6]. S. Basavarajappa, G. Chandramohan, K. Mukund, M. Ashwin and M. Prabu, "Dry Sliding Wear Behavior of $\mathrm{Al} 2219 / \mathrm{SiC}_{\mathrm{p}} / \mathrm{Gr}$ Hybrid Metal Matrix Composites", Journal of Material Engineering and Performance, Vol. 15 (6), pp. 668-674, 2006.

[7]. T. S. Srivatsan, I. A. Ibrahim, F. A. Mohamed, E. J. Lavernia "Processing Techniques for Particulate-Reinforced Metal Aluminium Matrix Composites",Journal of Material Science, Vol.26, pp.59655978, 1999.

[8]. W. Zhou, Z.M. Xu, "Casting of SiC reinforced Metal Matrix Composites", Journal of Materials Processing Technology, , pp.358 363, 1997.

[9]. J. Hashim, L. Looney, M. S. J. Hashmi, "Metal Matrix Composites: Production by the Stir Casting Method", Journal of Materials Processing Technology, 92 - 93, pp. 1-7, 1999.

[10]. J. Hashim, L. Looney, M. S. J. Hashmi, "Particle Distribution in Cast Metal Matrix Composites-Part I", Journal of Materials Processing Technology, 123, 2002, pp. $251-257$.

[11]. Z.Y. MA, "Friction Stir processing technology: A Review", Metallurgical and materials Transactions A, Vol. 39 A, pp.642-658, 2008.

[12]. Z. Wang, R.J. Zhang, "Mechanical behavior of Cast Particulate SiC/Al (A356) Metal Matrix composites", Metallurgical Transactions A, Vol. 22 A, pp.1585-1593, 1991.

[13]. Yan Jin, Li Chunzhi, Mi. Jiawei, Yan. Minggao, "Microstructure of $\mathrm{SiC}_{\mathrm{p}}$-Reinforced A356 Cast Al Metal-Matrix Composite", Journal of Materials Science, 28, pp. 6000-6006, 1993. 
[14]. N. Natarajan, S. Vijayarangan, I. Rajendran, "Wear behavior of A356/25SiC $\mathrm{p}_{\mathrm{p}}$ Aluminium Matrix Composites Sliding against Automobile Friction Material", Wear, 261, pp.812-822, 2006.

[15]. S. C. Tjong, S.Q. Wu, "Wear Behavior of An Al-12\% Si alloy reinforced with a low Volume Fraction of $\mathrm{SiC}$ particles, Composites science and technology", 57,pp.1551-1558,1997.

[16]. V. Constantin, L. Scheed, J. Masounave, "Sliding Wear of Aluminum-Silicon Carbide Metal Matrix Composites", Journal of Tribology ASME, 121, pp.787-794, 1999.

[17]. J. M. K. Kwok, S.C. Lim, "High Speed Tribological Properties of Some $\mathrm{Al} / \mathrm{SiCp}$ Composites: I Wear Mechanisms", Composites Science and Technology, 59, pp.65-75, 1999.

[18]. S. Wilson, A. T. Alpas, "Wear Mechanism Maps for Metal Matrix Composites", Wear, 212, pp. 41-49, 1997.

[19]. F. Akhlaghi, A. Zare-Bidaki, "Influence of graphite Content on the Dry sliding and oil Impregnated sliding Wear behavior of Al 2024graphite Composites Produced by in Situ-powder Metallurgy Method", Wear, 266, pp. 37-45, 2009.

[20]. J. B. Yang, C. B. Lin, T. C. Wang, H.Y. Chu, "The Tribological Characteristics of A356, $2 \mathrm{Al}$ alloy/Gr Composites”, Wear, 257, pp. 941-952, 2004

[21]. G. Rajaram, S. Kumaran, T. Srinivasa Rao, M. kamaraj, "Studies on High Temperature Wear and its Mechanism of Al-Si/graphite Composite under Dry Sliding conditions", Tribology international, 8 , pp.1-7, 2010

[22]. M. L. Ted Guo, C-Y.A. Tsao, "Tribological Behavior of SelfLubricating Aluminium/SiC/graphite hybrid Composites Synthesized by the Semi-Solid Powder-densification Method", Composite Science and Technology, 60, pp. 65-74, 2000 .

[23]. A. R. Riahi, A. T. Alpas, "The Role of Tribolayers on the Sliding Wear Behavior of Graphitic Aluminum Matrix Composites", Wear, 251, pp. 1396-1407, 2001.

[24]. L. Jinfeng, J. Longtao, Wu. Gaohui, T. Shoufu, C. Guoqin, "Effect of Graphite Particle Reinforcement on Dry Sliding Wear of SiC/Gr/A Composites", Rare Metal Materials and Engineering, 38, pp.1894-98, 2009.

[25]. J. Leng, L. Jiang, Q. Zhang, "Study of Machinable SiC/Gr/Al Composites, Journal of Materials Science", 43, pp.6495-99, 2008

[26]. S. Suresha, B. K. Sridhara, "Friction Characteristics of Aluminium Silicon Carbide graphite Hybrid Composites", Materials and Design, 34, pp. 576-583, 2012.

[27]. S. Basavarajappa, G. Chandramohan, "Dry Sliding Wear Behavior of Hybrid Metal Matrix Composites”, Material Science, Vol. 11, No 3, pp. 253-257, 2005.

[28]. M. Babic, B. Stojanovic, S. Mitrovic, I. Bobic, N. Miloradovic, M. Pantic, D. Dzunic, "Wear Properties of A356/10SiC/1Gr Hybrid composites in Lubricated Sliding Conditions", Tribology in Industry, 2, pp. 148-154, 2013.

[29]. B. Venkataraman, G. Sundararajan, "Correlation between the Characteristics of the Mechanically Mixed Layer and Wear Behavior of Aluminium, Al-7075 Alloy and Al-MMCs", Wear, 245, pp. 22-38, 2000.

[30]. M. R. Rosenberger, C. E. Schvezov, E. Forlerer, "Wear of Different Aluminium Matrix Composites under Conditions that Generate A Mechanically Mixed Layer", Wear, 259, pp. 590-601, 2005.

[31]. D. Lu, M. Gu, Z. Shi, "Materials Transfer and formation of Mechanically Mixed Layer in Dry Sliding Wear of Metal Matrix Composites Against Steel", Tribology Letter, 6, pp. 57-61, 1999.

[32]. X.Y. Li, K. N. Tandon, "Microstructural Characterization of Mechanically Mixed Layer and Wear debris in Sliding Wear of an Al Alloy and an Al based Composite", Wear, 245, , pp. 148-161, 2000.

[33]. A. L. Kearney, "Properties and Selection: Nonferrous Alloys and Pure Metals", Vol. 2,10 ${ }^{\text {th }}$ edition, ASM Handbook, ASM International, pp. $164-165,1990$.

[34]. B. Daniel, Miracle and L. Steven Donaldson, "Composites", Vol.21, $10^{\text {th }}$ edition, ASM Handbook, ASM International, pp. 838-867, 2001.

[35]. Song Min, "Effect of Volume Fraction of SiC particles on Mechanical Properties of SiC/Al Composites", Transaction Nonferrous Metals Society, China, 19, pp. 1400-1404,2009.

[36]. S. Elomari, M.D.M. Skibo, A. Sundarrajan, H. Richards, "Thermal Expansion Behavior of Particulate Metal Matrix Composites", Composites Science and Technology,58, pp.369-376, 1998.

[37]. L.H. Dai, Z. Ling, Y.L. Bai, "Size Dependent Inelastic Behavior of Particle Reinforced Metal Matrix Composites", Composites Science and Technology, 61, pp.1057-1063, 2001.

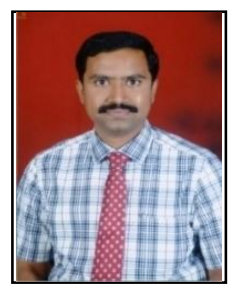

B. M. Viswanatha, is born on $27 / 06 / 1978$, from Tiptur, India. M.Tech graduate from Kuvempu University, India.. Currently working as Associate professor and HOD in Department of Mechanical Engineering, Kalpataru Institute of TechnologyTiptur, Karnataka, India. He handles subjects of Thermodynamics, turbo machines, hydraulics and pneumatics, Nontraditional machining, Computer aided engineering drawing etc., $\mathrm{He}$ is pursuing $\mathrm{Ph} . \mathrm{D}$ in Visvesvaraya Technological University-Belagavi, Karnataka, India. He has published research articles in reputed international peer reviewed journals.

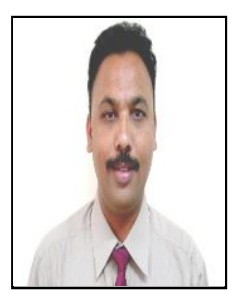

Dr. M. Prasanna Kumar iscurrently working as Associate Professor, Department of Studies in Mechanical Engineering, University BDT College of Engineering, Davanagere, Karnataka, India. He teaches subjects of Material Science and Metallurgy, Manufacturing process, Computer aided engineering drawing, hydraulics and pneumatics, Nontraditional machining, Mechanical Measurements, Optimization Technique etc., He holds Ph.D degree from Kuvempu University, Karnataka, India. He has published research articles/chapters in many reputed international peer reviewed journals.

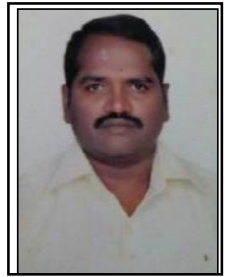

Dr. S. Basavarajappa iscurrently working as Registrar, IIIT-Dharwad, Karnataka, India. He worked in various capacities such as academic dean, academic senate member of Visevsaraya Technological University, Belagavi, Kranataka, India. He holds Ph.D degree from PSG-Tech, Coimbatore, Tamilnadu, India. He has published several research articles/chapters in reputed international peer reviewed journals. His research article/chapters having outstanding records in the field of composite materials. He has achieved Awards/Honors/Recognition from many organization/universities/Journals. He is editorial member/ reviewers for many international Journals.

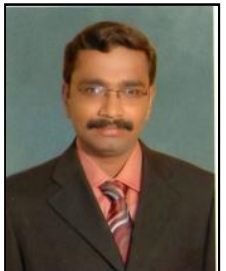

Dr. T. S. Kiran is currently working as Professor, Department of Mechanical Engineering, Kalpataru Institute of Technology-Tiptur, Karnataka, India. He teaches subjects of Design, Finite Element Methods, Advanced Machine Design, Automobile Engineering, Control Engineering, Computer aided Machine drawing etc., $\mathrm{He}$ holds $\mathrm{Ph} . \mathrm{D}$ degree from Visvesvaraya Technological University-Belagavi, Karnataka, India. He has published research articles in reputed international peer reviewed journals. 